\title{
Music, Architecture and Mathematics in Traditional Iranian Architecture
}

\author{
Ali Tokhmechian' ${ }^{1}$ - Minou Gharehbaglou' ${ }^{1}$
}

Published online: 26 May 2018

(C) Kim Williams Books, Turin 2018

\begin{abstract}
Architecture usually excites the audience through its special physique or structure. Using the arts such as music or utilizing digital mathematics science related to architecture could lead to the creation of special work of art. The aim of this article was to find a relationship between music and architecture and mathematics and the analysis of the parameters of this relationship in traditional Iranian architecture. To answer these questions, this article followed a qualitative research method along with comparative analysis and logical reasoning in theoretical studies and effective parameters. Accordingly, the present study is aimed to investigate the relationships and commonalities between music and architecture and mathematics and the various theoretical approaches in this regard. Then, there is a part studying the similarities between music and architecture and mathematics in traditional Iranian architecture. The results revealed that there is a deep, conceptual, and fundamental connection between music and traditional Iranian architecture the appearance of which is obvious in analysis and investigation of different parameters such as rhythm, high and low, hierarchy, numbers, mathematics, geometry, and color indicating compatibility of two or manifold presence of concept, physics and mathematics. Thus, the connection between parameters of "music-architecturemathematics" relationship in traditional Iranian architecture could be divided to two main approaches. In the conceptual-physical approach, elements such as color, rhythm, music, and high and low are important in traditional architecture. In the concept of mathematical-physical approach, elements such as numbers and symbolism.
\end{abstract}

Ali Tokhmechian

A.tokhmechian@tabriziau.ac.ir

Minou Gharehbaglou

M.gharehbaglou@tabriziau.ac.ir

1 Faculty of Architecture and Urbanism, Tabriz Islamic Art University, Tabriz, Iran 
Keywords Music $\cdot$ Architecture $\cdot$ Mathematics $\cdot$ Traditional $\cdot$ Iranian

\section{Introduction}

"Architecture and music are two very different forms of art: One is the manifestation of physical matter in order to solve practical problems, the other one tries to create emotions and pleasure along a physical absence" (Klemmt 2012: 3 ). The discussion of the relationship between architecture and music goes back a long time ago to their respective origins. According to Professor Sven Sterken, an expert in architectural history, architectural theory and history of urbanism who has a special interest in spatial, multimedia works by Iannis Xenakis, these speculations take place in two spheres: intellectualism and phenomenology. The former dates back to Greek philosophers and their problems with form and structure. In the latter case, the most elaborate paradigm is the theory of harmonics, with a rational link to metaphysics and a similar focus on numerical principles, which reached its peak in the Renaissance with numerous architects and musicians who sought to shape the form of architecture and music (Sterken 2007). There is indeed a very deep relationship between music and architecture and even mathematics! Some believe that architecture is an expression of music, but in its extension or evolvement while some others consider architecture as the frozen music-mathematics in the space (Tokhmechian et al. 2017: 109-110).

This study aimed at answering this question: What parameters could be analyzed and investigated in the relationship between "Music and Architecture and Mathematics" in traditional Iranian architecture? To answer this question, this article followed a qualitative research method along with comparative analysis and logical reasoning in theoretical studies and effective parameters. As a result, it is an attempt to probe into the relationship and commonalities between music and architecture and mathematics and the various theoretical approaches in this regard. For that reason, micro-elements involved in music and architecture such as rhythm, harmony, high and low, etc. are explained.

\section{Approaches to the Analysis of Relationships Between Music, Architecture and Mathematics}

In this section, a comprehensive approach known as division approach is presented, using all classifications and approaches that classify the relation between these two, taking into account all conceptual and visual aspects in cooperation with other sciences. Integration and use of multiple approaches to introduce a new approach is not impossible.

\section{Figurative-Symbolic Approach}

In this approach, music may have metaphorical, structural and even perceptual approaches. However, the attention to its symbolic and figurative dimensions is 
Table 1 Transformation into digital materials

\begin{tabular}{|c|c|c|c|c|c|c|}
\hline MIDI & $>$ & ASCII & $>$ & EXCEL & $>$ & CATIA \\
\hline music & & text & & numbers & & form \\
\hline
\end{tabular}

evaluated at first and in line with the decoration of an architectural work. This is because not every architectural work is known to everyone (Capanna 2009: 269). It should also be remembered that the initial or visual perception of each building serves as the first building block of perception for the audience. So, for example, given that the use of notes and their duration or time, "harmonic constructions", "dissonance", "disharmonies" and "thematic inversions" in the appearance of buildings are the most obvious methods for creating a musical sense at Steven Holl's Stretto House (Capanna 2009: 269). If a spectator with some degree of familiarity with music and musical notation looks at it, his or her mind will start perceiving the musical-architectural connections.

Music could be turned into digital materials in a process. In the following processing, music files including notes turn into text files. Then, these files are changed to classified excel documents and are entered into Catia software (Table 1).

\section{Physical-Digital Approach}

"Arc diagrams" of significant Europeans music pieces by Martin Wattenberg (2016) are among other artistic works to be mentioned. He calls them "Transparent curved Figures" visualization as an adaptive pattern-like algorithm is used to find repeated sequences and display them (Wattenberg 2016). Other examples of this approach are found in (Wingler 1969) and (Levy 2003). Therefore, it can be said that this approach is related to the external entirety or the body of architecture insofar as the digitizing or the computer-aided form of music is conducted in general terms such that its components, i.e. the notes, will not have an independent concept individually.

\section{Physical-Individual Approach}

In this approach, music is used as a concept in interior and exterior of architectural components and a combination of both. This music is more dominant inside the building and therefore, the architect pays more attention to the interior than the exterior. The use of harmonic rhythmic spaces, spaces with different materials and technologies, different kinds of shadows, spaces with parametric design in which light and sound are seen as if they are scattered patterns are taken into considerations. For example, the Monastery of La Tourette design alternatives to achieve the ultimate form. In addition to having music in the appearance of the building, this form is mainly designed to highlight the interior space of the monastery (Sterken 2007). 


\section{Physical-Conceptual Approach}

This is a combination of two previous approaches meaning that music is present both in the exterior and interior of the building. The Phillips World Expo is known for the advancement of music and combining it with architecture. Le Corbusier worked only on the development of interior design and the exterior design was done by Greek designer Iannis Xenakis who was also an experimental composer. Xenakis turned Corbusier's Modulor into graph-shapes with logical ratios (Variego 2011: 69-70). So, a combination of music series is formed as a pavilion for displaying electronic technology (Valle et al. 2010).

\section{Introspective Physical-Conceptual Approach}

The entrance of light to religious places could relate to religious music in this approach. As light beams in old mosques in Iran might represent the beauty of light and shadow, these rhythms are the fullness and emptiness of the body that result in religious Sufi music in these spaces. Examples of light used in sacred spaces include the colorful glass in Iranian orosi in 63 columns in the Mosque of Tabriz, and the cut-out cross in the Church of the Light by Tadao Ando.

\section{Numerical-Musical-Mathematical Approach}

The connection of mathematics with music could be observed by melody, harmony, harmony and arrangement of notes, rests, scales or combinations of emotional notes. "Musical-mathematics" is music and math side by side, complementary to each other. The discovery of a hidden geometry in the depth of Jelokhan ${ }^{1}$ combined with Iranian Dastgahi ${ }^{2}$ music and mathematics reflects its architect's adherence to the principles of music and math in the architecture of this mosque (Tokhmechian et al. 2017: 126). Examples of this are found in Leon Battista Alberti's design for San Sebastian in Mantua, where numerical values masterfully shape the ratio of 3:5 (Sarhangi 1998; Volpi Ghirardini and Livio 2015). Another example is found in the Jelokhan of Sheikh Lotfollah Mosque (Tokhmechian et al. 2017: 122).

\section{Applying the Physical-Conceptual Approach to Iranian Architecture}

Iran, the ancient land of the Aryans, located in the heart of the Middle East, dating back several thousand years ago and with unique architectural features, is of special value compared to the architecture of other countries. Its key features consist of intelligent design, detailed calculations, measured form, compliance with technical and scientific issues in the building, and finally various ornaments that represent the glorious architecture of the land despite their simplicity (Fig. 1).

\footnotetext{
1 Jelokhan is a space proceeding the entrances in some buildings.

2 Dastgah (Persian: دستخاه) is a musical modal system in traditional Persian art music.
} 

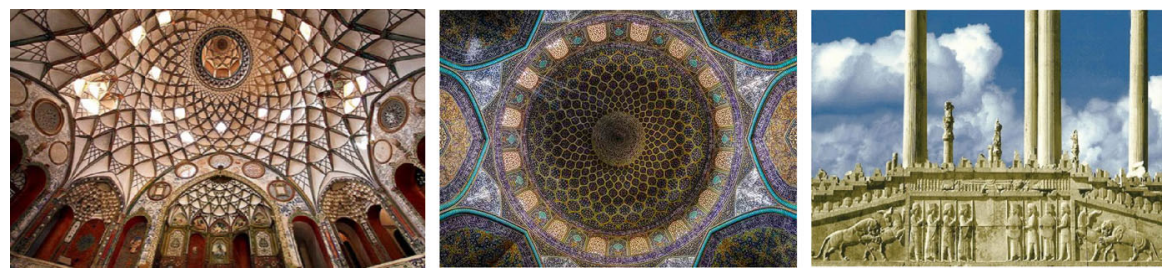

Fig. 1 A part of Iranian top architecture over time, from left to right: Persepolis in the ancient city of Parseh in the Achaemenid Empire, Sheikh Lotfollah Mosque of Isfahan of Safavid Empire (www.Kojaro. com) \& Boroujerdiha House in Kashan related to the Qajar monarchy

Iranian architecture is more than just form and style. In fact, it is the achievements of cultural and environmental factors that for thousands of years expressed the lifestyles of different classes of the Iranian people. Deeply-rooted Iranian architecture has reached multiple achievements after centuries of evolution and change, and its analysis is attractive and noteworthy for various reasons. Choosing Iran for a case study to examine the relationship between music, architecture and mathematics could be influenced by many factors and examining some of these parameters is done using division approach described in the previous section. Therefore, classifying Iranian architecture data in this section shows that some approaches such as physical-conceptual and physical-conceptual-mathematical are abundant in Iranian architecture. Due to large analytical scale and writing limitations, we attempted to study and analyze the parameters of the two introduced approaches.

\section{Highs and Lows}

\section{Musical Expression}

High and low pitches in music notes in the $\mathrm{G}$ (treble) and $\mathrm{F}$ (bass) clefs are shown in Fig. 2. In the $\mathrm{G}$ clef shown, $\mathrm{C}^{4}$ and $\mathrm{G}^{5}$ are respectively the lowest and highest musical notes.

\section{Architectural Expression with Analysis}

Architecture as well as music has high and low points. Windward Mansion of Dolat Abad in Yazd, with the tallest windward ${ }^{3}$ in the world, represents highest point of the building and ground level and below indicates the lowest point. Over the centuries, high and low points have been used in design of many buildings in the world including towers, skyscrapers, minarets, ${ }^{4}$ temples, etc. (Tokhmechian et al. 2017: 111-112) (Fig. 3).

\footnotetext{
3 Windward or windcatcher (Persian: بادكير, badgir=bad "wind"+gir "catcher") is a traditional Persian structure to catch natural air into the building.

4 Minarets (Persian: مناره) are a distinctive architectural structure akin to a tower and typically found adjacent to mosques.
} 

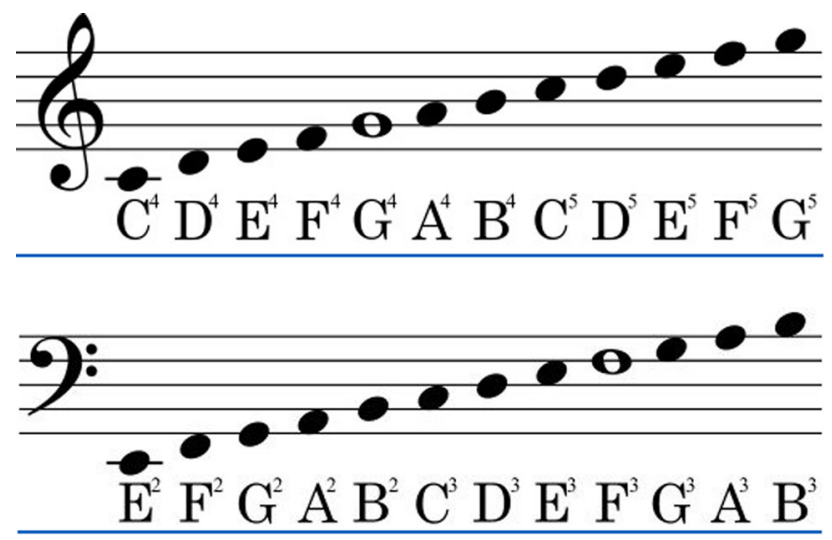

Fig. 2 The range of used music notes in the G clef (above) and the F clef (below) (www.ezmusictheory. com)

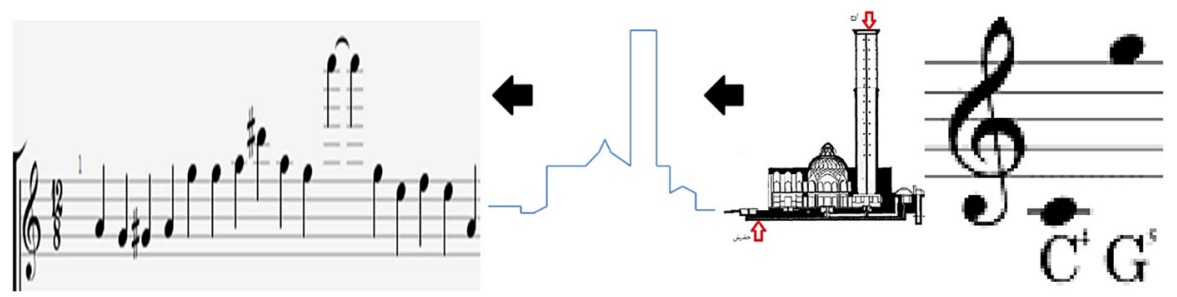

Fig. 3 Similarities between high and low points in music and architecture (Tokhmechian et al. 2017: 112)

\section{Rhythm}

\section{Musical Expression}

The main value in the art of music is the rhythm of the song, which is simply the division of time. Each piece of music needs a leash first of all in order to keep track of rhythm and prevent melodies diffusion. In terms of music, this leash is called weight or rhythm. Rhythm means order, arrangement, repetition and sequence. In some kinds of music such as Iranian Radif ${ }^{5}$ music, the rhythm is free, but it does not mean there is no rhythm present (Elhamian and Eftekhari 2006) (Fig. 4).

\section{Architectural Expression and Analysis}

Rhythm is the regular and coordinated recurring, uniform or non-uniform lines, forms and elements in order to organize the architectural form which is usually visible in the most architecture components. Its coordinated repetition, which is

\footnotetext{
${ }^{5}$ Radif (Persian: رديف) is a collection of many old melodic figures. The Radif contains several different dastgahs which are distinguished from each other by their relationship of note intervals and the form of the movement of the melodies within them.
} 


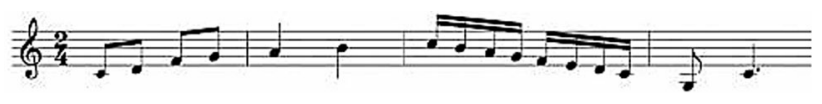

Fig. 4 Rhythmic changes according to note value

common in the linear type, causes the formation of flattened curves, organized gardens, and multiple windows. This repetition could be classified depending on the uniformity or non-uniformity, frequency or progression (Tokhmechian et al. 2017: 111) (Fig. 5).

The periodic-evolutionary rhythm that is visible in the fractal-like Asemaneh ${ }^{6}$ of the Aminoddole Timcheh ${ }^{7}$ in Kashan could be compared to a music piece. This could be a part of the rising of Iranian musical notes in a Goosheh ${ }^{8}$ (or corner) of Iranian music or a harmonic rise. The last line similarity note of Fig. 6 with the architecture of Aminoddole Timcheh fractal Asemaneh in Kashan is in a way that the a segment of Fig. 6 was like chambers' architecture definition and the B segment of Fig. 6 implies the rhythmic and regular narrowing of notes representing the arising geometry and tiny Timcheh fractal canopies.

\section{Hierarchy}

\section{Musical Expression}

In Iranian Dastgah music, for playing an instrument or a performing a song, this order must be followed: Dar-amad, ${ }^{9}$ Avaz, ${ }^{10}$ Tasnif, ${ }^{11}$ Reng. ${ }^{12}$ However, later innovated by the late Darvish Khan, ${ }^{13}$ Pish-daramad ${ }^{14}$ and Chahar-mezrab ${ }^{15}$ was added to this hierarchy as well.

\footnotetext{
6 Asemaneh: a special ceiling form. In Persian literature applying the term "Asemaneh" (Persian: آسمانه) which means ceiling and is rooted in the word "Aseman" or sky, indicates the ethereal aspect of the Iranian ceilings.

7 Timcheh: bazaar. Timchehs have a semi-public Persian-Islamic traditional urban space. "Moharram"(Pourjafar \& Sadraee 2015).

8 Goosheh: melody. A dastgah (Persian: دسنگاه) may contain approximately from 10 to 30 gooshehs. The principal gooshehs (Persian: كوشه) of the dastgah specify the different scales within that dastgah.

9 Dar-amad: The first goosheh in each dastgah or avaz is called the dar-amad (Persian: درآمد), which explores and establishes the main mode of that dastgah or avaz with lowest sound extension (Bam note).

10 Avaz: (Persian: آواز) is improvised rhythmic-free singing.

11 Tasnif (Persian: تصنيف), rhythmic accompanied by singing, an ode.

12 Reng (Persian: رنگ) is closing rhythmic composition, a dance tune.

13 Darvish khan (Persian: درويشخان) was a talented Persian classical musician and a Tar player. He added a sixth string to this instrument in order to extend its tuning possibilities and to enhance its sound.

14 Pish daramad: (Persian: بيش درآمد), a free-standing composition played at the beginning of a performance. This was invented by Darvish khan.

15 Chahar-mezrab is (Persian: جهارمضراب) rhythmic music, but rhythmic-free or without singing; created by legendary Darvish khan.
} 

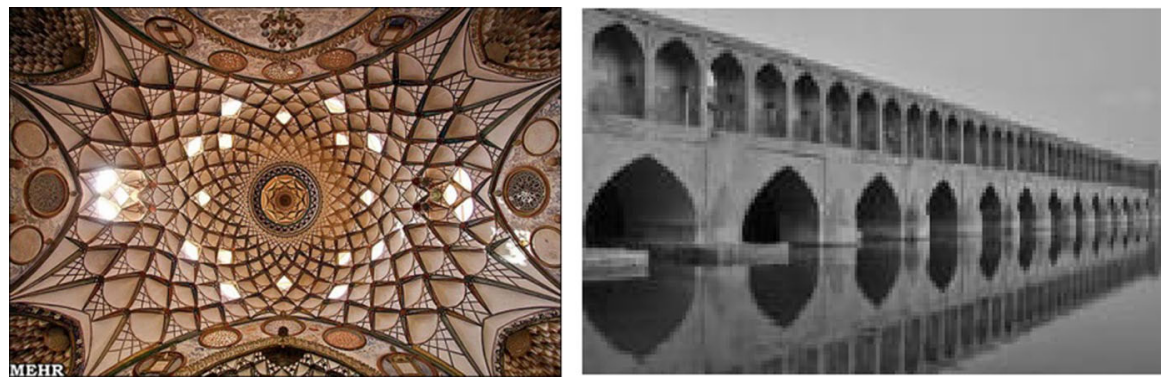

Fig. 5 a, Left Asemaneh evolutionary rhythm in Boroujerdiha House in Kashan (www.Etoood.com); b, right regular and consistent rhythm in $\mathrm{Si-O}-\mathrm{se} \mathrm{Pol}$ in Isfahan (www.e-architect.ir)
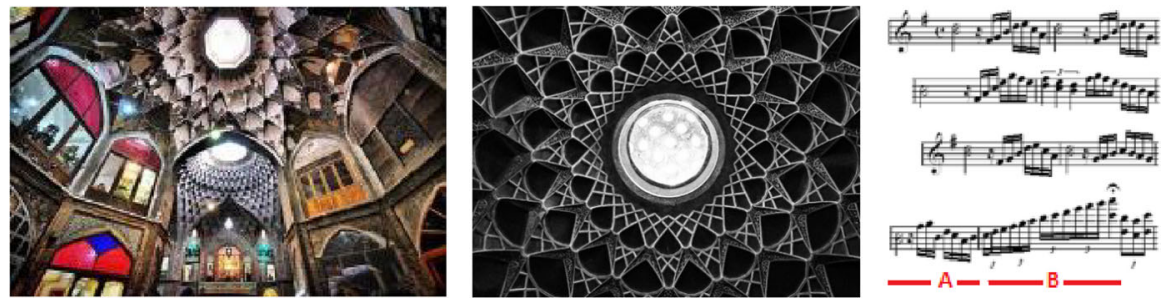

Fig. 6 From left to right: a Aminoddole Timcheh (www.gardeshgariiran.ir); b Aminoddole Timcheh Asemaneh (dokmehzard.aminus3.com); c musical excerpt consisting of segments A and B

\section{Architecture Expression and Analysis}

Hierarchy is one of the basic principles governing the collections, objects, and phenomena that either exist naturally in the universe as a whole or are designed and created by human beings (Tabibian et al. 2012). For example, in an Iranian garden, the layout of spatial elements and physical divisions follows hierarchical principles and rules. Hierarchy and classification of Iranian garden includes entrance mansion, entrance Nazargah, ${ }^{16}$ corridor, entrance porch, main belvedere, Andaruni mansion, ${ }^{17}$ Biruni mansion, ${ }^{18}$ and Anadruni Nazargah. Further, in the Iranian house, Hashti ${ }^{19}$ is a definition of direct and indirect entrance to the public, private and semi-public spaces in order to respect confidentiality of meeting, lighting or light variety, Nazargah and various resting places represent hierarchy and classified spaces in each section of architecture (Fig. 7).

\footnotetext{
${ }^{16}$ Nazargah: In order to achieve the wide and deep vision surrounded intuitively by natural elements, the Persian garden, creates two groups of landscapes by making the main mansion in the highest location or located with maximum dominance: The first group creates interior landscapes that creates in subsidiary and main axes of garden, and other group creates exterior landscapes and infinite vision to the existence natural landscapes in the garden around. These landscapes creating with reference to site environmental capability and using lofty Nazargah (Persian: نظركاه) in the main mansion (Nattaj and Rezazadeh 2016).

${ }^{17}$ In traditional Persian residential architecture, the andaruni (Persian: اندرونى) is in contrast to the biruni, and is a part of the house in which the private quarters are established.

${ }^{18}$ Biruni (Persian: بيرونى) is in contrast to andaruni.

19 Hashti (Persian: هنتى), is the space one behind the sar-dar (doorway).
} 

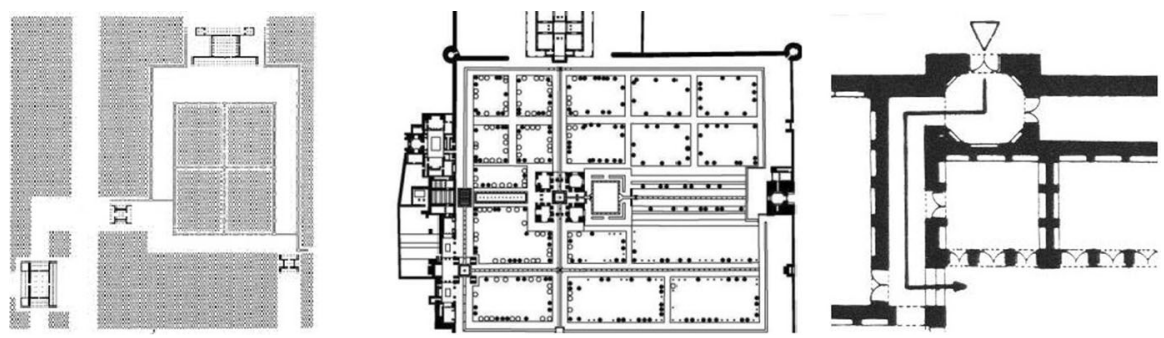

Fig. 7 From left to right: The hierarchy of entering Cyrus private garden, the hierarchy of Fin Garden in Kashan, and hierarchy of accessibilities through Hashti and corridor in a house in Naeen (www.ashwood. ir)

Dar-amad in Iranian music is the same as entrance to Iranian Garden meaning that the definition of pre-entrance, entrance, entrance mansion, or Nazargah is similar to the existence of Pish-daramad or Dar-amads (first, second, and third). Chahar-mezrab and Reng in the hierarchy of Dastgah music acts as water in ponds, fountains, rivers, pools and geysers in the garden or playing with light and color in the mirror, decorating, painting, and woodcarving of the main building. The presence of these physical and conceptual similarities in these hierarchies is easily visible.

\section{Color}

\section{Musical Expression}

Frequency and period of rotation is a common feature in colors, music, nature, universe, etc. Just as the circle color results from the separation of white light into distinct colors, the separation of the musical octave results in seven distinct note; in the eighth note, identical to and an octave higher than the first, repetition occurs. Matching colors with music is complex and relative and there is a significant difference from the first matching to that of Isaac Newton. Over three centuries after that attributing sound to the colors were accompanied with various attractive arguments (Fig. 8).

\section{Architecture Expression and Analysis}

Color is a charming and wonderful element in Interior design, facade design, urban furniture, urban landscape, etc. Color could be relaxing, exciting, or misleading and give an updated definition of the architecture of different monuments. Colored and patterned glass reminds us of beautiful and colorful Iranian architecture. These windows are more common in historical monuments, mosques, and old Iranian houses, which augment their beauty when the sun shines on themm resulting in spectacular design and stunning colors. These glasses make wonderful images by passing the light through them (Fig. 9). 

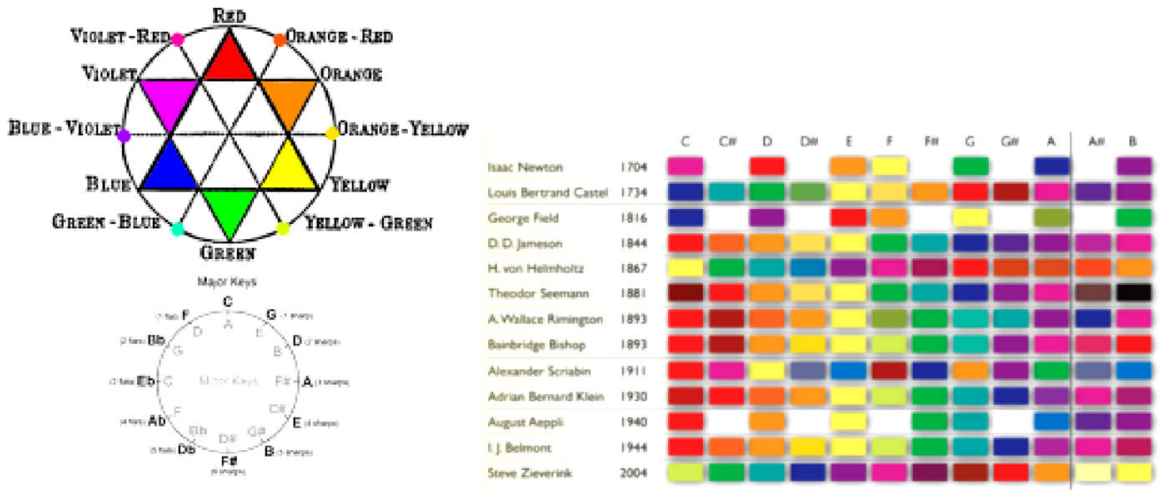

Fig. 8 From left to right: the system considered in this research, matching colors with music in common model (www.dailyspeculations.com), matching colors with the music in the last three centuries (Collopy 2009)
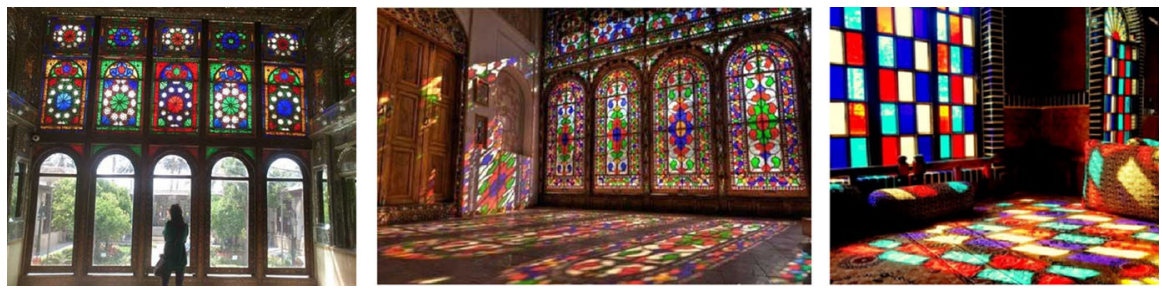

Fig. 9 Colorful glass in Iranian architecture and Orosi has an especially celebrated position (www. bistsotoon.com)

Color and light are among the most important and influential aspects involved in traditional Iranian architecture, represented by colorful glass and orosi. ${ }^{20}$ Artificial color or the use of light in different colors were a part of Iranian life and has graced living, spiritual, and work places. Light in is an undeniable element in Nasir-ol-Molk Mosque in Shiraz as a strong and symbolic concept of Iranian architecture. The resulting quality of architectural space inside this mosque is so powerful that the spectator is overwhelmed (Fig. 10).

Regarding the use of each color, according to the illustrated color circle shown in Fig. 11, it could be deduced that all the colors are used to a same amount while blue, red, green, and orange are used in the mosque representing these notes: blue depicts $\mathrm{G \#}$ (or $\mathrm{A} \square$ ); red represents $\mathrm{C}$; green illustrates F\# (GD); and orange is portrays D\# (or E $\square$ ) (Maryon 1924: 38). The authors various random investigations regarding the attribution of the notes with classical music, based on some basic rules, are as follows: due to centrality of blue color in the circle under the curves, the first priority of the piece note is $\mathrm{G \#}$ (or $\mathrm{A} \square$ ). The $\mathrm{C}$ note representing red is used for the second part of the piece and D\# is the third section. The green color depicting F\# (or $\mathrm{G} \square$ ) is the note's final section. In this way, two main colors in the circle of colors,

\footnotetext{
${ }^{20}$ Orosi (Persian: ارسى) is one of the useful innovations, which has been used for many centuries in order to control the harsh sunlight, make space colorful and beautiful in Iran.
} 

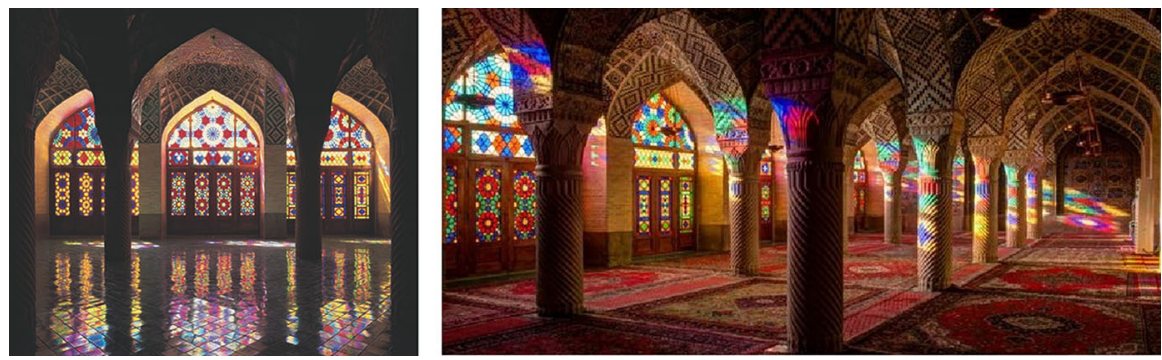

Fig. 10 Nasir ol Molk Mosque in Shiraz, a manifestation of color and light play (www.kojaro.com)
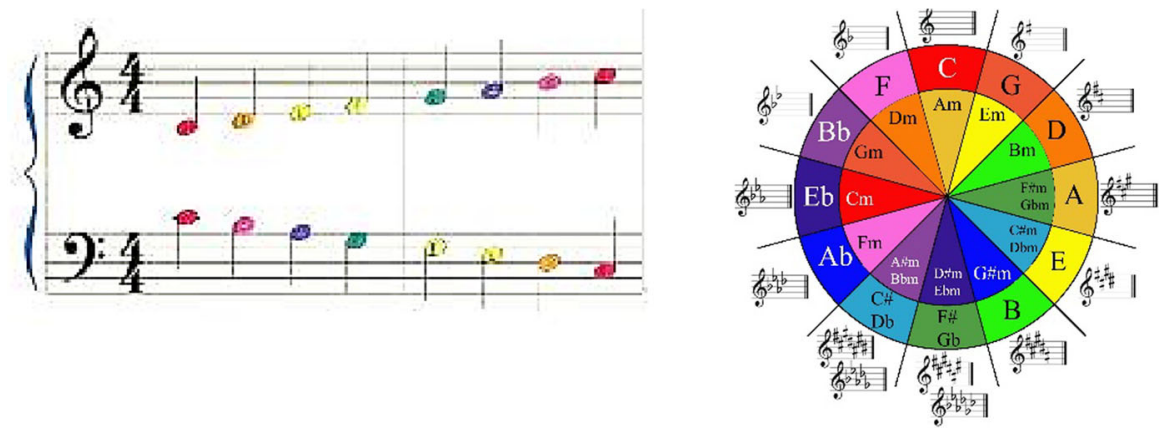

Fig. 11 The circle of fiths, matching colors and music notes, writing notes based on colors (www. musicians-helper.com)

blue and red, are prioritized and the other two colors, orange and green, come next in order. If we consider G\# note as the observer (or Shahed) note (level 4) in Shur Dastgah $^{21}$ while C note as level 7, D\# note would be the beginning of dang and Shur first level, and F is at the third Shur level (level 3) (Fig. 12). Therefore, making Iranian classical Shur Sol Dastgah in the sides of this window could represent an ideal, a very beautiful and poetic state that invites man to silence and thought. The similarity of human passion and need to pray to the Lord with Shur Dastgah is not a coincidence and is a sign of a higher, more principled system in Iranian architecture.

\section{Element Reflection}

\section{Musical Expression}

Carrier lines could display different arrangements of notes. The following figure illustrates the reading notes' method from left to right. In the first bar, a musical sixteenth scale starts from D and peak at of the contralto of notes scale called $\mathrm{E}$ and then there is a return to $\mathrm{D}$. Then, there is reflective symmetry of notes to the vertical line and in the second bar, there is twice usage of thirty-second notes,

21 Shur Dastgah or Dastgah-e shur (Persian: دستخاه شور) is one of the seven Dastgahs of Persian Music. 

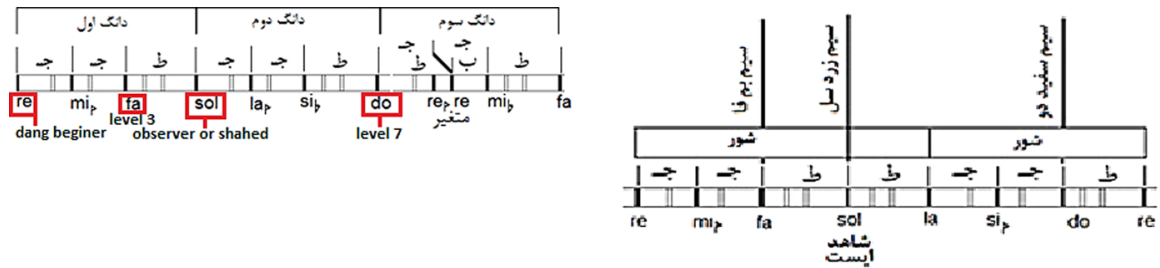

Fig. 12 From left to right: Dariush Talayee Shur Sol, Three dang system based on Vazizri Gam increase in the second dang in a full loop by Majid Kiani (source: Author)

each of which have their individual reflective vertical axis along with overall reflective axis (3 reflective axes), or in the third bar, in which two parallel notes having reflective broken axis, and finally, in the fourth bar in which two sets of notes lead to the creation of reflective horizontal axis regardless of making reflective vertical axis.

\section{Architecture Expression and Analysis}

In most Iranian architectural spaces, the juxtaposition of physical elements provides an overall view or visual entirety whereby the components are arranged based on the principles of centrality, symmetry, balance, parallelism and other ordered frameworks. In such cases, the overall architecture and the final image are taken into account in the perception of the general landscape (Ardalan and Bakhtiar 2012). Some of these visual totalities including their physical elements and their symmetrical reflections in water-can be placed in a circle to study their symmetrical axes (Figs. 13, 14).

General form, plans, design lines, and linear decorations could each have a number lines or curves that make the reflection visible in their details or entirety. Reflection in the architecture as the reflection in notes is also present in Iranian Qatarbandi. $^{22}$ Horizontal muqarnas $^{23}$ work has a special rhythm and weight and is performed at a certain defined height on the wall. The structural similarity between Qatarbandi and the musical notes of the scale is obvious as a general order, general rhythm, minor order, and minor rhythm (Fig. 15).

\section{Ornament}

\section{Musical Expression}

Sounds are the only toolbox of a musician, however, the creator later pays an extra attention to his work after the combination of sounds in melodies and adds some small notes among the sounds that cause beauty and ornament. Thus, ornament notes are tools for beauty and elegance of musical melodies and songs (Khaleghi 2014: 143) (Fig. 16).

\footnotetext{
22 Qatarbandi (Persian: قطاربندى) is a horizontal muqarnas.

${ }^{23}$ Muqarnas (Persian: مقرنس) is a form of architectural ornamented vaulting.
} 


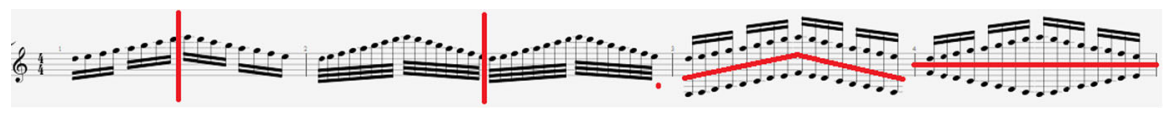

Fig. 13 Horizontal, vertical, skewed, overall vertical, and solo vertical within notes (source: Author)
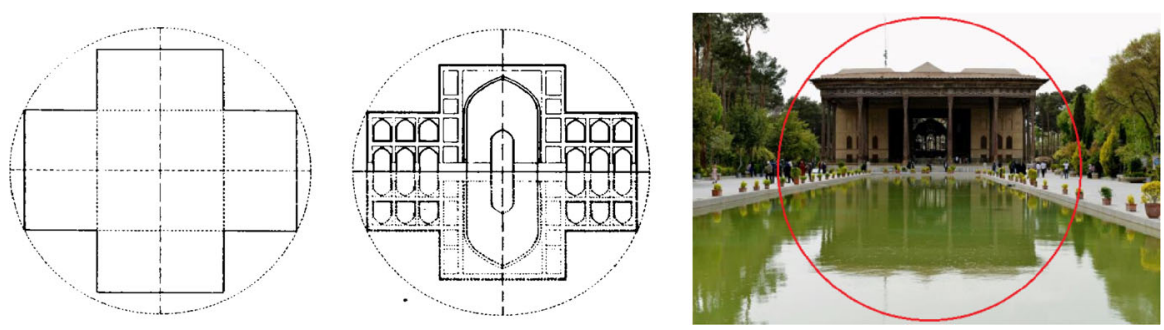

Fig. 14 Left and middle: Water reflection in building and completing circle frame (Ardalan and Bakhtiar 2013), right: Full circle of Iranian Chehel-sotun Garden in Isfahan (www.karnaval.ir)
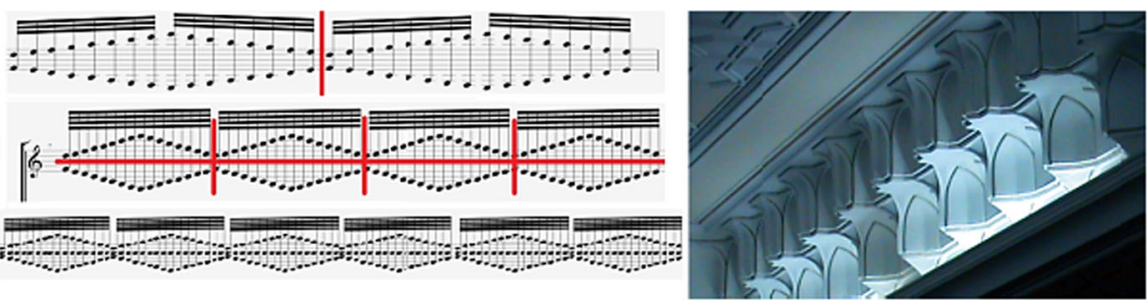

Fig. 15 Reflection in the architecture in the form of Iranian Qatarbandi and the similarity with reflection in musical scales (source: Author)

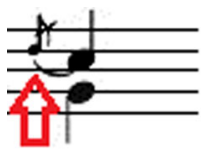

Fig. 16 Ornament note that is before or after the main note and is used to beautify the melody (source: Author)

\section{Architecture Expression and Analysis}

The use of flowers and plants such as rose bushes, vines, violets, and asters, which is common in Iranian traditional architecture, serves decorative, pharmaceutical, medical, and psychological purposes. Thus, adorning is a matter of taste and depends on Iranian culture and therefore is the same as ornament notes in Iranian classical music (Fig. 17). 

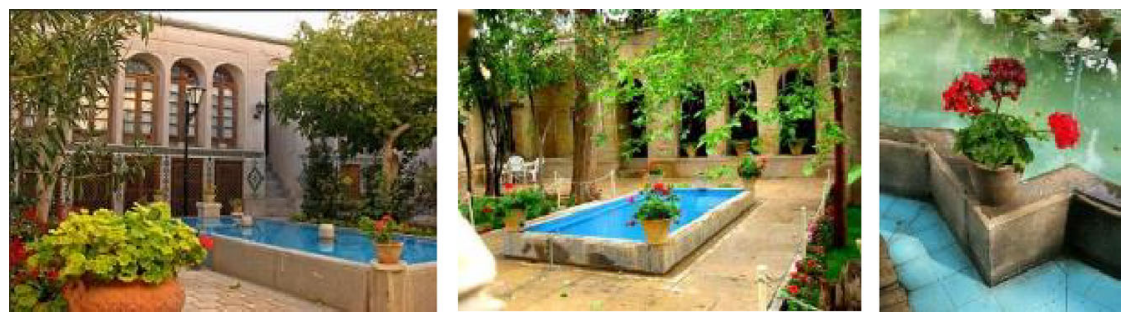

Fig. 17 The use of geranium flowers beside the water element goes back to Iranian traditional architecture (source: Author)

\section{Applying the Physical-Conceptual-Mathematical Approach to Iranian Architecture}

\section{Numbers and Distances}

\section{Musical Expression}

Numbers play a main role in the formation of notes' duration. Whole, half, quarter, sixteenth, thirty-second and sixty-fourth notes and rests are all defined based on a particular time interval (Figs. 18, 19).

\section{Architecture Expression and Analysis}

Numbers have different distances to one another. Numbers make up different mathematical ratios with respect to each other. Some numbers may create Fibonacci sequence or the golden ratio; others may relate to musical ratios related to time; still others are attributed to structural skeletons in architecture. The usage of numbers in

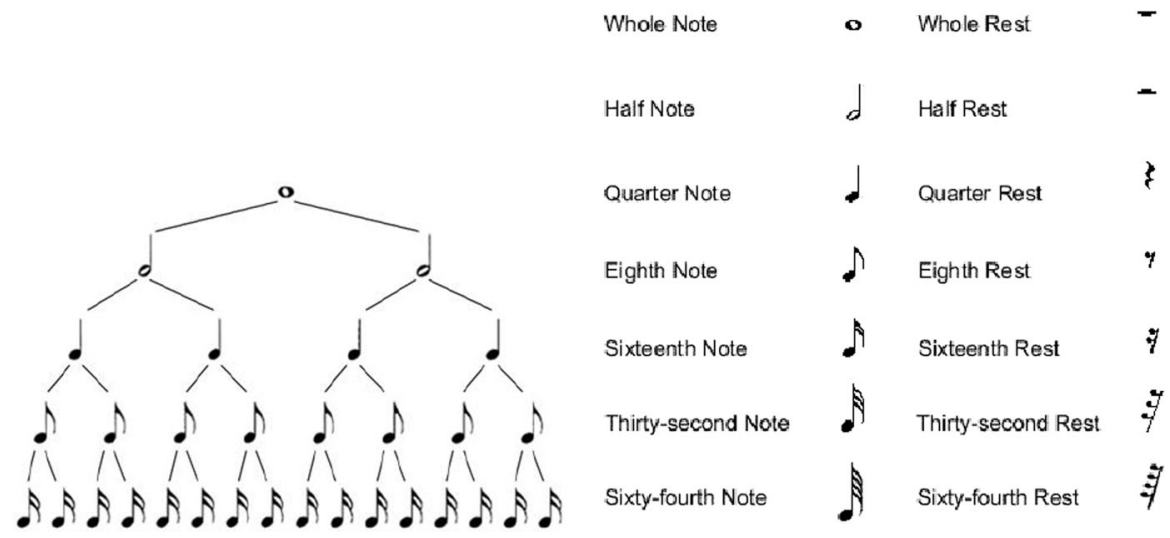

Fig. 18 The time value of musical notes (www.ihoosh.ir). The whole note is the primary note in valuation and its division forms the basis for the values of the other (the half note's value is half the whole note, the quarter note's value is half the half note, etc.). viewed as numbers, these values are $1,1 / 2,1 / 4$, $1 / 8,1 / 16,1 / 32$, and so on. Accordingly, divisions by the number 2 characterise these values 


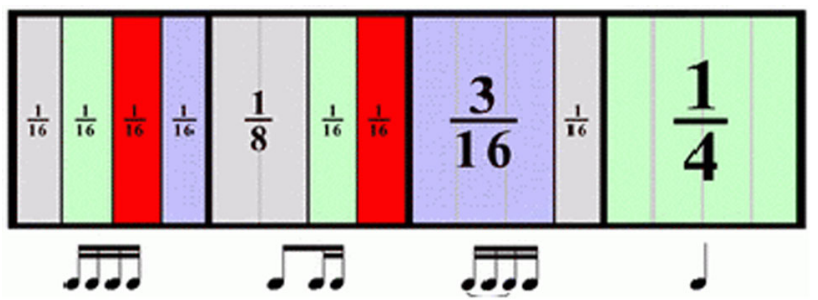

Fig. 19 Display of the time fractions and the division of notes from whole to sixteenth (www. playpianomusic.com)

Iranian architecture dates back as far in history as the golden ratio. For example, masterful usage of this ratio in Tajolmolk Dome in Isfahan (Fig. 20b, c) led Eric Schroeder (1939) to name it the most beautiful dome in Iran (Pope et al. 1938: 201). In Isfahan, the Ali-Qapu Mansion (Fig. 20a) is no exception here and the usage of golden ratio is obvious in its façade (Hejazi 2009). So we see that using divisions based on the golden ratio is the design criteria for some of the well-known Iranian architects. Fractions resulting from the golden ratio in this building could represent divisions of time in a musical piece composition (Tokhmechian et al. 2017: 115) (Fig. 21).

\section{Numbers and Numerical Symbolism}

\section{Musical Expression}

As mentioned earlier, the half note's value is half the whole note and the quarter note's value is half the half note, meaning that the whole note was division source and number 1 is attributed to it. Divisions based on 2 are calculated related to the whole note, so physical symbolism could be achieved through the introduction and acceptance of some rules. This symbolism could be done via some notes in the shape of symbols representing 1/8, 1/4, 1/2, 1, 2, and 4 (Fig. 22).

Aside from notes' physical symbolism, depending on the distance between each other or with respect to weight and rhythm resulting from each other, one could also
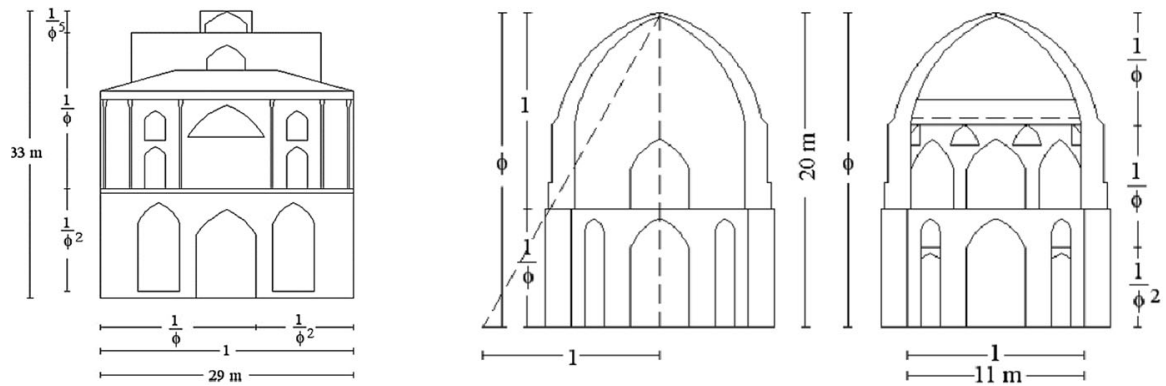

Fig. 20 a, Left: the façade of Ali-Qapu Mansion in Isfahan; b middle and c right) Tajolmolk Dome in Isfahan with the embedded golden ratio (Hejazi 2009) 


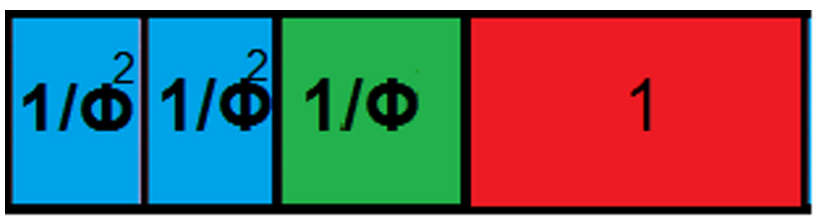

Fig. 21 Divisions based on the golden ratio: display of size fractions used in Tajolmolk Dome in Isfahan like fraction in a piece note (Tokhmechian et al. 2017)

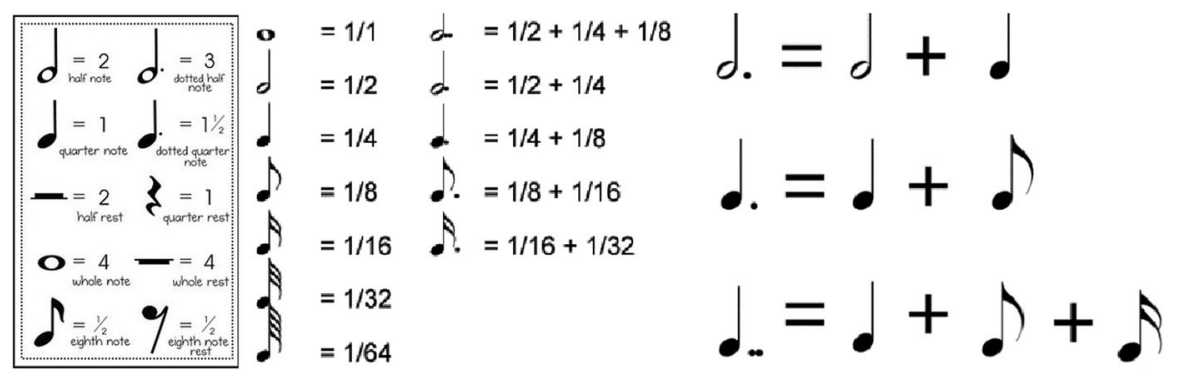

Fig. 22 Time value and formula equality of different notes' time value as physical symbolism (source: Author)

consider physical symbolism in a conceptual matter. For example, in classical Iranian music, the source of the $\mathrm{C}$ note in Mahoor ${ }^{24}$ Dar-amad is some kind of symbolism and its details leads to a command unit such as the relationship between the creations and the Creator (Tokhmechian et al. 2017) (Fig. 23).

\section{Architecture Expression and Analysis}

The numbers in ancient Islamic, traditional and even contemporary Iranian architecture might depict different symbols. Number oneThe number 1 could emphasize a point or the only God. The number 2 might represent the principle of duality, while the number 4 may illustrate four major or minor directions, four gardens (chahar-bagh), four known elements, the four sides of a square. The square symbolizes of balance and perfection (Burckhardt 1994; Madadpour 1992). In particular, we might refer to compositions of square, Garivband ${ }^{25}$ and dome in Iranian mosques, which in spite of their simplicity and plainness of the form, are very well-established and important elements in Iranian mosques' architecture. Between the dome and the square under it, there is an intermediary. The dome could be built by generally an octagonal base called Garivband on the building's walls that are quadrilateral. This Garivband can be thought of as a physical representation of the number 8 . The dome, on the other hand, has been used as a symbol of the universe over the course of history in various nations and civilizations. The dome is a model of the celestial sphere that is placed over a quadrilateral base which

\footnotetext{
${ }^{24}$ Dastgah-e Mahoor (Persian: دستخاه ماهور) is one of the seven Dastgahs of Persian Music.

${ }^{25}$ Garivband (Persian: كَريوبن is a connection between dome and shabestans' walls.
} 


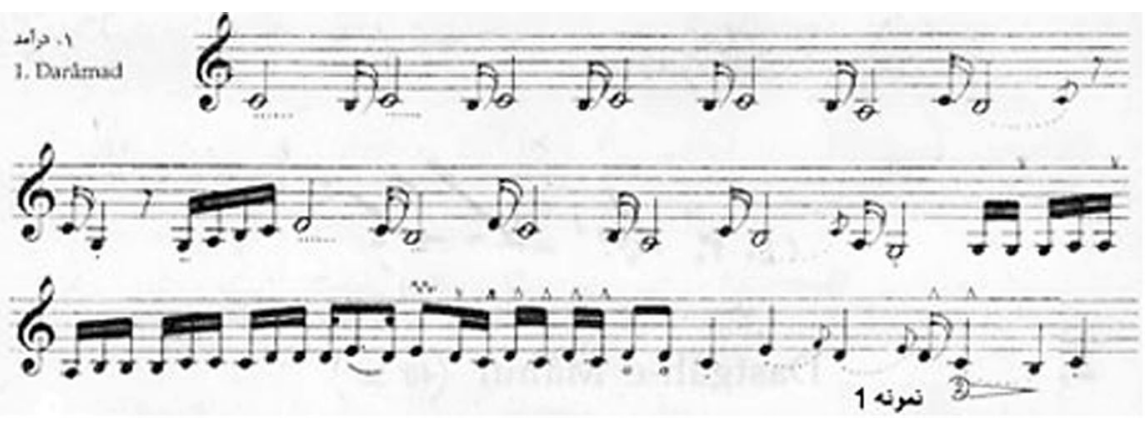

Fig. 23 Mahoor Dar-amad (source: Author)

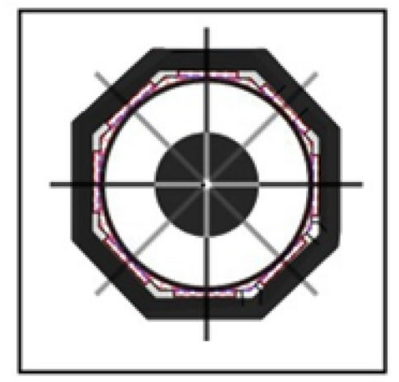

Sc $-1: 100$

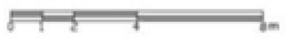

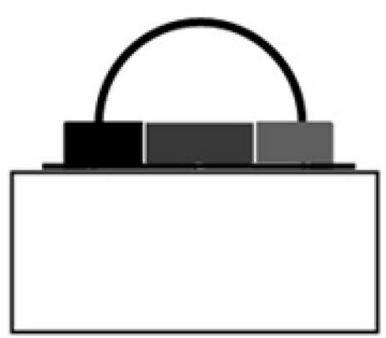

$\mathrm{Se} .1: 100$

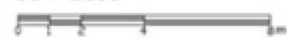

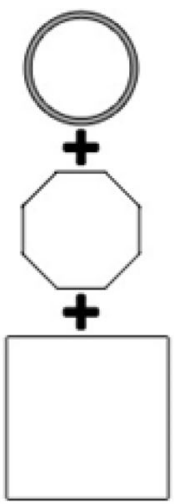

Fig. 24 The existence of spiritual music in the heart of numbers and symbolism of the mosque (source: Author)

indicates the principle of unity. This is a symbol of the Lord governing his creations and his infinitely large universe, against which one man is almost nothing. Physically and conceptually the dome could represent numbers 16, 32, 64, 128, and infinity. Using multiples of the number 2 in the symbolism of the dome is due to the circle's $n$-gon regular form and it is defined like this for its leading towards infinity and its creation. Through the symbolism, the number two could be related to two sides of the direction of prayer in mosques. In general, considering number one and infinite as a symbol of the Lord in the beginning and the end, Numerical symbolism of Shabestan, ${ }^{26}$ square under the dome, and the dome, Garivband, and the square under the dome will be like $1,2,4,8,16$ (infinity). Thus, it is possible that conceptual note used in the design of mosques would be $\mathrm{C}$ (Whole), D (half), $\mathrm{E}$ (quarter), F (eighth), C (sixteenth).

\footnotetext{
26 Shabestan (Persian: شبستان) is an underground space that can be usually found in traditional architecture of mosques, houses, and schools in ancient Iran.
} 
The $\mathrm{C}$ note has been seen as the symbol of the Lord and another note could be considered. Besides, middle notes could be any notes provided that the time period is observed (Fig. 24).

\section{Conclusion}

Expression of the relationship between music and architecture and mathematics in the first section of the present study led to the presentation of physical-symbolic, physical-digital, physical-singular, physical-conceptual, physical-introspective-conceptual, and numerical-musical-mathematical approaches. Then, in the following sections, the relationships between music, architecture, and mathematics in Iranian traditional buildings were explored through the applications of two of these approaches. In the physical-conceptual approach different elements such as color, rhythm, high and low were investigated in music and Iranian traditional architecture. In the physical-conceptual-mathematical approach, various components were analyzed including numbers and symbolism. The findings suggested that Iranian architects from ancient times tried using all human life sciences as the existence of advanced mathematics, complex geometries, extremely precise music, which are accessible to everyone today, is visible in the architecture of Iran's traditional, historic, and ancient buildings.

Acknowledgements All images not by the author have been included under the Fair Use regulations.

\section{References}

Ardalan, Nader and Laleh Bakhtiar. 2013. The Sense of Unity: The Sufi Tradition in Persian Architecture, 2nd ed. Kazi Publications.

Burckhardt, Titus. 1994. Sacred Art. Farsi Trans. Jalal Satari. Tehran: Nashr markaz publication.

Capanna, Alessandra. 2009. Music and Architecture: A Cross between Inspiration and Method. Nexus Network Journal 11(2): 257-271. https://doi.org/10.1007/978-3-7643-8976-5_8.

Collopy, F. 2009. Playing (with) color. Glimpse: The Art and Science of Seeing 2 (3):62-67.

Elhamian M. and Mohammad Eftekhari. 2006. Music Theory. Mahoor Institution, Tehran.

Hejazi, M. 2009. Sacred Geometry in Nature and Persian Architecture. History of Science 6(2):17-44.

Khaleghi, Rouhollah. 2014. Sargozasht-e Musighi-e Iran (History of Persian Music). Vol 2. Tehran: Safi alishah (in Farsi).

Klemmt, Christoph. 2012. Anisotropia. http://orproject.com/files/pdf/ChristophKlemmt-Anisotropia.pdf. Accessed 13 Apr 2018.

Levy, Adrián J. 2003. Real and Virtual Spaces Generated by Music. International Journal of Architectural Computing 1(3): 375-391.

Madadpour, Mohammad. 1992. Spiritual Thought and the Field of Art (in Persian). Tehran. Sorush. p. 152.

Maryon, Edward. 1924. Marcotone: The Science of Tone-Color. Boston: C. C. Birchard \& Co.

Nattaj, Heydar Vahid and Eshagh Rezazadeh. 2016. The Complex of Water, plant and Nazargâh: Looking for an Archetype of Persian Garden. Manzar 7(33): 48-55.

Pope, Arthur Upham and Phyllis Ackerman. 1938. A Survey of Persian Art from Prehistoric Times to the Present London and New York: Oxford University Press.

Pourjafar, Ali and Ameer Sadraee. 2015. Comparative Analyses of Various Types of Uncovered Timchehes with Emphasis on Timcheh Sarafian. Urban management 14(40): 7-21. 
Sarhangi, Reza, ed. 1998. Bridges: Mathematical Connections in Art, Music, and Science. Conference Proceedings 1998. Winfield, Kansas: Southwestern College. https://doi.org/10.1007/s00004-9980016-y.

Schroeder, Eric. 1939. The Seljuq Period. In: A Survey of Persian Art from Prehistoric Times to the Present, Arthur Upham Pope and Phyllis Ackerman, eds., 2:981-1046. London and New York: Oxford University Press.

Sterken, S. 2007. Music as an Art of Space: Interactions between Music and Architecture in the Work of Iannis Xenakis. In: Resonance: Essays on the intersection of Music and Architecture, eds. Mikesch W. Muecke and Miriam S. Zach, vol. 1, 31-61. Ames: Culicidae Architectural Press.

Tabibian M., Charbgoo, N. and Ensie Abdolahimehr. (2012) the Principle of Hierarchy Reflection in Islamic Iranian Cities. Armanshahr 4(7):63-76.

Tokhmechian, Ali., Gharehbaglou, M. and Ahad Nejad Ebrahimi. 2017. The Formation of Space by the Conceptual Link of Music-Math and Architecture: A Case Study of Jelokhan and Asemaneh of Sheikh Lotfollah Mosque in Isfahan. Journal of researches in Islamic architecture 5(2):108-129 (in Farsi).

Valle, Andrea, Kees Tazelaar and Vincenzo Lombardo. 2010. In a concrete space. Reconstructing the Spatialization of Iannis Xenakis Concret Ph on A multichannel setup. Proceedings of SMC 2010 (Sound and Music Computing). http://smcnetwork.org/files/proceedings/2010/40. Accessed 13 Apr 2018.

Variego, Jorge Elias. 2011. Architecture in Motion: A Model for Music Composition. Ph.D. Dissertation, University of Florida.

Volpi Ghirardini, Livio G. 2015. The Numerable Architecture of Leon Battista Alberti as a Universal Sign of Order and Harmony. In: Architecture and Mathematics from Antiquity to the Future, Kim Williams and Michael J. Ostwald, eds., vol. 1, 645-661. Cham: Springer.

Wattenberg, Martin. 2016. Arc Diagrams: Visualizing Structure in Strings. http://hint.fm/papers/arcdiagrams.pdf. Accessed 13 Apr 2018.

Wingler, H. M. 1969. Bauhaus: Weimar, Dessau, Berlin and Chicago. MIT Press.

Ali Tokhmechian an Iranian architect and researcher, received his master's degree in Islamic Architecture from Tabriz Islamic Art University in 2017. His research interests include the fields of music, architecture, Islamic architecture and environmental psychology. He has started extensive research on music and architecture since the beginning of his graduate studies and has managed to publish some of his papers in prestigious domestic and international journals. He is also looking forward to publishing more on music and architecture.

Minoo Gharehbaglou is an Associate Professor at the School of Architecture and Urbanism, Tabriz Islamic Art University. She received her PhD in architecture from the University of Tehran in 2012. Gharehbaglu was selected twice, in 2007 and 2014, as the best researcher of Tabriz Islamic Art University and also in 2010 as a superior, well-educated woman in East Azarbaijan province, Iran. Her research is mainly focused on environmental psychology and perceived spatial characteristics. She has published/ presented over 70 articles in this field in national and international scientific journals and congresses. By the time of this publication, Gharehbaglou has supervised and counseled for more than 10 doctoral theses and 45 master's dissertations. Her translation of Robert Gifford's 2016 book, Research Methods for Environmental Psychology, to Persian is currently under publication. 